\title{
Predictors and colonoscopy outcomes of inadequate bowel cleansing: a 10-year experience in 28,725 patients
}

\author{
Fadi Abu Bakera*, Amir Marib*, Smadar Nafrina, Muhammed Sukia, Baruch Ovadiaa, Oren Gala, \\ Yael Kopelamna
}

Hillel Yaffe Medical Center, Hadera; Nazareth EMMS Hospital, Bar Illan University, Israel

Abstract

\section{Introduction}

Adequate preparation of the colon is essential for the optimal visualization of the colonic mucosa, and effective bowel

Department of a Gastroenterology and Hepatology, Hillel Yaffe Medical Center, Hadera, Israel, Affiliated to the Technion Faculty of Medicine, Haifa, Israel; ${ }^{\mathrm{b}}$ Gastroenterology, Nazareth EMMS Hospital, Affiliated to the Faculty of Medicine, Bar Illan University, Israel

${ }^{*}$ Fadi Abu Baker and Amir Mari contributed equally to the study

Conflict of Interest: None

Received 30 March 2019; accepted 5 June 2019; published online 6 July 2019

Correspondence to: Amir Mari, MD, Hashalom st 1, 38100 Hadera, Israel, e-mail: amir.mari@hotmail.com

DOI: https://doi.org/10.20524/aog.2019.0400 preparation is directly correlated with the safety, accuracy, quality, and duration of the colonoscopy procedure [1-4]. Multiple bowel preparations exist, with the ideal preparation being effective, safe, convenient and tolerable. Most of the available preparations can produce satisfactory cleansing results with acceptable tolerance, though the results for individual patients are variable. Despite the wide heterogeneity and variable data, the overall results from the available studies and meta-analyses do not indicate a clear advantage for one specific agent over another. As a result, no regimen has been universally adopted [5-13].

Unfortunately, bowel preparations are inadequate in up to $25-30 \%$ of examinations $[14,15]$. This may increase the risk of adverse events related to the procedure, lengthen the procedure time, and be inversely related with cecal intubation and adenoma detection rates [16,17]. An inadequate level of preparation entails a greater cost and creates a drain on endoscopic resources because of the 
need for early repetition of the procedures and the longer procedure duration [18].

The reported predictors of inadequate bowel preparation include previous inadequate bowel preparation, inpatient status, advanced age, comorbidities, and polypharmacy [19-24]. An awareness of these risk factors, as well as identifying others, can direct physicians to implement measures to manage patients at risk and to use more efficacious or tailored regimens $[25,26]$. In the current study, we reviewed the bowel preparation before colonoscopy in a large cohort over a 10 -year period, to identify the risk factors for poor bowel preparation and to better characterize this population.

\section{Patients and methods}

We conducted a retrospective, large cohort study, which examined consecutive patients who underwent a colonoscopy over a 10-year period in the gastroenterology department at the Hilell Yaffe Medical Center, a University-affiliated hospital in Israel. Patients who had a full data set, including demographic details (age and sex), procedural setting (inpatient/outpatient), indication for the procedure, regimen and quality of bowel preparation, depth of examination, and endoscopic findings, were included in the final analysis. All patient data were collected from the department's electronic record system. Arab and non-Jewish patients were included as minority populations. The indication for the procedure was derived from the examination report. For a few of the patients, multiple indications were recorded. In this case, we reviewed the clinical reports and scanned referral letters, and selected the dominant and direct indication for referral for an endoscopy.

Patients were included if they had a bowel preparation with standard, commonly used, polyethylene glycol (PEG)-based (Meroken $\odot$, MoviPrep $\odot$ ) or picosulfate-based (Picolax $\odot$ ) regimens. Bowel preparations with a fleet enema, bisacodyl tablets or any other non-widely acceptable bowel cleansers (such as phosphate-containing regimens) were excluded. Meroken is a high-volume (4 L) 3350 PEG cleansing solution with sulfite and Moviprep is a 3350 PEG low-volume (2 L) preparation with ascorbic acid. Patients were given the same written instructions for diet recommendations and purgative handling for each preparation regimen. Patients were directed to use split-dose consumption in the Picolax $\odot$ and MoviPrep $\odot$ regimens, while one-dose consumption was the mainstay instruction for the majority of patients who performed a preparation with Meroken $\odot$.

Patients under the age of 18 years old, as well as patients with missing data, were excluded.

For the assessment of the bowel preparation, a uniform institutional scale with 5 categories was used, and the preparation was categorized as poor (a large amount of fecal residue precludes a complete examination), inadequate (feces or turbid fluid prevent a reliable examination), fair (moderate amount of stool that can be cleared with suctioning permitting an adequate evaluation of entire colonic mucosa), acceptable (small amount of turbid fluid or feces not interfering with the examination), and good (small amount of clear liquid with a clear mucosa seen). The preparation quality was later classified accordingly as "adequate preparation" (good/acceptable/fair) or "inadequate preparation" (poor/inadequate).

The patients were divided into 2 groups according to the adequacy of the bowel preparation. We performed a multivariate analysis to identify the effect of multiple variables on the bowel preparation, including demographics, setting, indication, and preparation regimen. In addition, to identify the effect of bowel preparation on the outcome of the procedure, we compared the polyp detection rate and cancer detection rate, as well as the cecal and terminal ileum intubation rates, in both groups. We carried out a multivariate analysis to account for the variability caused by age, sex, setting, the indication of the procedure and the quality of the bowel preparation, as these could potentially affect the outcome of the procedure.

\section{Statistical analysis}

Descriptive statistics, in terms of the mean, standard deviation and percentiles, were derived for all parameters in the study. Differences between the 2 groups (adequate vs. non-adequate preparation) in the quantitative parameters were tested using Student's $t$-test, while Fisher's exact test was used for the categorical parameters. Chi-square tests with an adjusted P-value (Bonferroni method) were applied to evaluate the differences between the 2 groups (adequate preparation vs. non-adequate preparation), the three preparation regimens (MoviPrep, Merokem and Picolax) and the patients' stratified age groups $(<50,51-70$ and over 70 years). Several multivariate logistic regression models with forward selection were used to determine the effect of the independent parameters associated with the polyp detection rate, cancer detection rate, terminal ileum, and complete examination rates. SPSS version 25 was used for the statistical analysis. $\mathrm{P}<0.05$ was considered as significant.

\section{Results}

A total of 31,210 procedures in the study period were reviewed. Of these, 2485 patients (7.9\%) did not meet the inclusion criteria and were excluded as follows: 981 (3.1\%) were under the age of 18, 940 (3\%) used a non-standard bowel preparation, and the other 645 (2\%) did not have a full data set. Thus, a total of 28,725 patients were included in the study, of whom $6702(23.3 \%)$ were considered to have inadequate bowel cleansing and were classified as the inadequate bowel preparation group. The baseline characteristics of both groups are summarized in Table 1 . The groups differed with regard to demographic data: the inadequate preparation group had a higher mean age $(62.7 \pm 14.1$ vs. $56.7 \pm 14.1$ years; $\mathrm{P}<0.01)$ and more male patients $(56.6 \%$ vs. $49.2 \%$; $\mathrm{P}<0.01)$ compared with the adequate group. Both the adequate and inadequate preparation groups included a small percentage 
Table 1 Baseline characteristics

\begin{tabular}{|c|c|c|c|}
\hline Characteristics & Adequate prep & Non adequate & P-value \\
\hline Age $($ mean \pm SD $)$ & $56.7 \pm 14.1$ & $62.7 \pm 14.1$ & $<0.01$ \\
\hline Male sex & $10,840(49.2 \%)$ & $3793(56.6 \%)$ & $<0.01$ \\
\hline Setting (outpatient) & $19,566(88.8 \%)$ & $5060(75.5 \%)$ & $<0.01$ \\
\hline Minority (Jewish) & $18,892(85.5 \%)$ & $5261(78.5 \%)$ & $<0.01$ \\
\hline \multicolumn{4}{|l|}{ Indication (N; \%) } \\
\hline Personal history of polyps & $1538(7.0 \%)$ & $610(9.1 \%)$ & $<0.01$ \\
\hline Abdominal pain/diarrhea & $5042(22.9 \%)$ & $1267(18.9 \%)$ & $<0.01$ \\
\hline Past colonic surgery & $656(3.0 \%)$ & $235(3.5 \%)$ & 0.15 \\
\hline Anemia/positive FOBT & $4024(18.3 \%)$ & $1581(23.6 \%)$ & $<0.01$ \\
\hline Rectal bleed & $2936(13.3 \%)$ & $858(12.8 \%)$ & 0.21 \\
\hline Screening & $1003(4.6 \%)$ & $214(3.2 \%)$ & $<0.01$ \\
\hline Constipation & $1605(7.3 \%)$ & $610(9.1 \%)$ & $<0.01$ \\
\hline Other & $4166(18.9 \%)$ & $1327(19.8 \%)$ & 0.084 \\
\hline \multicolumn{4}{|l|}{ Preparation regimen $(\mathrm{N} ; \%)$} \\
\hline MoviPrep & $4553(20.7 \%)$ & $1575(23.5 \%)$ & $<0.01$ \\
\hline Meroken & $2219(10.1 \%)$ & $1548(23.1 \%)$ & $<0.01$ \\
\hline Picolax & $3946(17.9 \%)$ & $1106(16.5 \%)$ & $<0.01$ \\
\hline Unknown & $11,305(51.3 \%)$ & $2473(36.9 \%)$ & $<0.01$ \\
\hline
\end{tabular}

of minority populations $(14.5 \%$ vs. $21.5 \%$; $\mathrm{P}<0.01)$ and the procedures were performed mainly in the outpatient setting ( $88.8 \%$ vs. $75.5 \% ; \mathrm{P}<0.01$ ), respectively. The inpatient setting represented only a minority of the total referred patients (15.9\%, 4572 patients). Overall, 55\% of the patients were referred from internal medicine wards and $45 \%$ from surgical wards.

The most common indications for a colonoscopy in both groups were abdominal pain and diarrhea (22\%), followed by anemia and a positive fecal occult blood test (19.5\%). However, although there was no noticeable difference in the procedure indications between the groups, a statistically significant difference was noted for several colonoscopy indications. A larger percentage of procedures in the inadequate preparation group were performed for a personal history of polyps $(9.1 \%$ vs. $7 \%$; $\mathrm{P}<0.01)$, anemia and a positive fecal occult blood test $(23.6 \%$ vs. $18.3 \% ; \mathrm{P}<0.01)$ and constipation $(9.1 \%$ vs. $7.3 \%$; $\mathrm{P}<0.01)$, but fewer for diarrhea and abdominal pain $(18.9 \%$ vs. $22.9 \% ; \mathrm{P}<0.01)$, and screening $(4.6 \%$ vs. $3.2 \% ; \mathrm{P}<0.01)$. In addition, as presented in Table 1 , both the groups varied in terms of the bowel preparation regimen used. The most frequently used regimen in both the groups was MoviPrep $\odot$, although data on the preparation regimen used was unavailable in many patients.

In the multivariate analysis of risk factors for inadequate preparation, as presented in Table 2, advanced age (odds ratio [OR] 1.015, 95\% confidence interval [CI] 1.013-1.017; $\mathrm{P}<0.01$ ), male sex (OR 1.353, 95\%CI 1.286-1.423; $\mathrm{P}<0.01$ ), and a minority population (OR 1.635, 95\%CI 1.531-1.746; $\mathrm{P}<0.01)$ were significantly associated with inadequate bowel
Table 2 Multivariate analysis of risk factors for inadequate bowel preparation

\begin{tabular}{lcccc}
\hline \multirow{2}{*}{ Characteristics } & \multirow{2}{*}{ P-value } & OR & \multicolumn{2}{c}{$95 \% \mathrm{CI}$} \\
\cline { 3 - 5 } & & & Lower & Upper \\
\hline Age & $<0.01$ & 1.015 & 1.013 & 1.017 \\
Male sex & $<0.01$ & 1.353 & 1.286 & 1.423 \\
Inpatient setting & $<0.01$ & 2.018 & 1.884 & 2.163 \\
Minority population & $<0.01$ & 1.635 & 1.531 & 1.746 \\
Indication & & & & \\
Personal history of polyps & 0.186 & 1.058 & 0.973 & 1.151 \\
Abdominal pain/diarrhea & 0.133 & 1.066 & 0.981 & 1.160 \\
Past colonic surgery & 0.02 & 1.266 & 1.089 & 1.472 \\
Anemia/positive FOBT & 0.11 & 0.900 & 0.802 & 1.009 \\
Rectal bleed & $<0.01$ & 1.473 & 1.355 & 1.602 \\
Screening & 0.471 & 0.947 & 0.815 & 1.099 \\
Constipation & $<0.01$ & 1.373 & 1.240 & 1.519 \\
Other & 0.356 & 1.042 & 0.955 & 1.138 \\
\hline
\end{tabular}

OR, odds ratio; CI, confidence interval; FOBT, fecal occult blood test

preparation. When the patients were stratified by age groups, ages 51-70 years and above 70 years old were significantly associated with inadequate bowel preparation (OR 1.445, 95\%CI 1.324-1.576 and OR 1.856, 95\%CI 1.679-2.051; $\mathrm{P}<0.01$, respectively), compared to those under 50 years old. 
The inpatient setting was prominently associated with inadequate preparation. In this setting, patients referred from internal medicine departments were more likely to have inadequate bowel preparation $(26.2 \%$ vs. $23.4 \%$; $\mathrm{P}<0.01)$ compared to surgery departments. With regard to the indications for the procedures, significant associations with an inadequate preparation were recorded for constipation (OR 1.373, 95\%CI 1.24-1.519; $\mathrm{P}<0.01$ ), rectal bleeding (OR 1.473, 95\%CI 1.355-1.602; $\mathrm{P}<0.01)$, and the surveillance procedures after colonic resection (OR 1.266, 95\%CI 1.089-1.472; $\mathrm{P}<0.01$ ).

Concerning the preparation regimens, compared to Picolax $\odot$, the MoviPrep $\odot$ preparation regimen did not differ significantly (OR 0.942, 95\%CI 0.869-1.021; $\mathrm{P}=0.147$ ). However, Meroken $\odot$ was significantly linked with inadequate bowel preparation (OR 1.541, 95\%CI 1.41-1.684; $\mathrm{P}<0.01$ ).

The evaluation of the outcomes of the procedure revealed that adequate bowel preparation was associated with an enhanced polyp detection rate $(26.8 \%$ vs. $23.6 \%$; OR 1.22 , 95\%CI 1.109-1.347; $\mathrm{P}<0.01)$, a better colorectal cancer detection rate $(2.8 \%$ vs. $2.4 \%$; OR $1.402,95 \%$ CI $1.146-1.716$; $\mathrm{P}<0.01)$, as well as higher rates of cecal $(96.4 \%$ vs. $73.5 \%$; OR 2.243, 95\%CI 2.095-2.403; $\mathrm{P}<0.01)$ and terminal ileum $(8.1 \%$ vs. 5.4\%; OR 1.243, 95\%CI 1.088-1.434; $\mathrm{P}<0.01)$ intubation.

\section{Discussion}

Recent advances in endoscopic procedures have led to improvements in both image enhancement and procedural performance. Inadequate bowel preparation is a leading cause of failed exams and hampers the performance of high-quality endoscopy. Reports in the literature indicate that inadequate bowel preparation is observed in approximately 25\% of all colonoscopies, but could be as high as 35-40\% [27].

In our study, we demonstrated that almost one quarter of patients referred for colonoscopy procedures are inadequately prepared. In our practice, patients with inadequate preparation are invited to repeat the procedure within 3 months to one year, depending on the procedure's indication, the grade of inadequacy and the procedure completion status. In this scenario, a large number of patients were brought back for repeat colonoscopies, which translated into a huge impact on the cost to the healthcare system and resource consumption.

In the current study, we reviewed our experience over the last decade, focusing on various risk factors that, from the clinician's point of view, contributed to poor bowel preparation. This is the first study in a series that aims to characterize this population, as a step towards implementing tailored preparation regimens in an attempt to improve the quality of bowel preparation in our practice. Regarding the demographic profile, we demonstrated that advanced age is associated (OR 1.015, 95\%CI 1.013-1.017; $\mathrm{P}<0.01)$ with an inadequate preparation, especially in the age group of patients above 70 years old compared to those under 50 (OR 1.856, 95\%CI 1.679-2.051; $\mathrm{P}<0.01$ ). Comorbidities, polypharmacy and reduced colonic motility, more prevalent in elderly patients, are suggested mechanisms [28-29].
In concordance with other reports [30], male sex (OR 1.353, 95\%CI 1.286-1.423; $\mathrm{P}<0.01$ ) was also linked to inadequate preparation. In addition, belonging to a minority population (OR 1.635, 95\%CI 1.531-1.746; $\mathrm{P}<0.01$ ) was significantly associated with an inadequate bowel preparation, apparently as a result of language and communication gaps. The inpatient setting was among the most prominent factors associated with poor bowel preparation (OR 2.018, 95\%CI 1.884-2.163; $\mathrm{P}<0.01)$. Acute disease, polypharmacy and urgent procedures may lead to difficulties in completing bowel preparation regimens. Moreover, narcotic use and protracted immobility may decrease gastrointestinal motility and are among the postulated explanations for inadequate bowel preparation [30,31]. We also found that, when classified by the referring department, patients hospitalized in internal medicine wards tended to be more inadequately prepared compared to those in surgical wards. This could possibly be explained by the variances in the medical background and procedural indications. The importance of staff experience and the awareness of the significance of bowel preparation, as well as staff education in this regard, cannot be underestimated.

In the current study, we demonstrated that several of the indications of the procedure and the clinical settings were linked with poor preparation. Constipation was significantly associated with inadequate cleansing (OR 1.373, 95\%CI 1.241.519; $\mathrm{P}<0.01$ ), consistent with similar findings from other studies [32]. Likewise, patients with rectal bleeding were less adequately prepared (OR 1.473, 95\%CI 1.355-1.602; $\mathrm{P}<0.01$ ), apparently because of the urgent nature of procedures in this setting. We could not, however, find other reports examining or confirming this finding. Similarly, Chung et al [23] demonstrated that past abdominal surgery was an independent predictor of an inadequate preparation, in concordance with our demonstration that surveillance procedures after past colonic surgery are associated with poor bowel preparation (OR 1.266, 95\%CI 1.089-1.472; $\mathrm{P}=0.02$ ).

With regard to bowel preparation regimens, we performed a comparison between 3 regimens commonly used nationally in recent years. We were surprised to find that Meroken $\odot$ ( $3 \mathrm{~L}$; PEG-based purgative) was associated with a more inadequate preparation compared to Picolax@ (OR 1.541, 95\%CI 1.41-1.684; $\mathrm{P}<0.01$ ), while the low volume MoviPrep $\odot$ ( $2 \mathrm{~L}$; PEG-based purgative) was not (OR 0.942, 95\%CI 0.869-1.021; $\mathrm{P}=0.147$ ). To investigate these findings in more depth, we reviewed the available instructions for all the regimens, including diet recommendations, purgative handling and timing before the procedure. The only noticeable difference was that patients receiving Meroken $\odot$ were instructed to drink it in one dose, while in the other regimens a split dose was recommended. This could explain the higher rate of poor preparations in this group, as a meta-analysis of 5 randomized controlled trials found that a split-dose regimen of PEG significantly enhanced the percentage of patients with adequate preparation, while this was also linked with increased patient compliance as well as decreased nausea [33].

Unsurprisingly, in the current study, we showed that colonoscopy performance is significantly affected by inadequate bowel preparation. Besides the reduced polyp detection rate and cecal intubation rate, also demonstrated in many other 
reports [34,35], we showed that the colorectal cancer detection rate, as well as the terminal ileum intubation rate, were significantly enhanced when patients were adequately prepared compared with the poorly prepared patients. Thus, our study confirms the negative effect of inadequate preparation on the efficiency and outcome of the colonoscopy in routine clinical practice.

The strengths of our study include the large cohort involved, the inclusion of different multiple indications and settings reflecting real-world practice, as well as the comparative evaluation of several preparation regimens. Our study has limits inherent in its retrospective nature. Other possible factors, such as patient history, background diseases and medications that might have impacted the bowel preparation, were not included. Data on the preparation regimen used were unavailable in many patients. In addition, we acknowledge that no precise data about the use of whole-dose day-before and split-dose preparation were available to us because of the retrospective nature of the study; this is an important limitation. Our study focused on the clinician's point of view and did not include patient-related factors such as compliance with dietary modifications, the timing of bowel purgative administration, water consumption and appointment waiting time for the colonoscopy, among other factors that may have impacted outcomes. We did not use an internationally validated scoring system for the bowel preparation, although we used a scale similar to the validated Aronchick scale.

In conclusion, we have demonstrated the low diagnostic yield and outlined the various factors associated with inadequately prepared procedures. Further studies are under way to examine tailored preparation regimens in this setting.

\section{Summary Box}

\section{What is already known:}

- Inadequate bowel preparation is a leading cause of failed colonoscopy, causing an inconvenient experience for the patients and an economic burden

- Old age, constipation, and immobility are well-known risk factors for inadequate bowel preparation

\section{What the new findings are:}

- Several risk factors for an inadequate bowel preparation were observed, including increased age, male sex, minority populations, past colonic surgery, as well as rectal bleeding and constipation indications

- Inpatient procedures are associated with a greater risk of poor bowel preparation

- Poor preparation was associated with poor colonoscopy quality indicators and a lower rate of colorectal cancer detection

\section{References}

1. Rex DK, Petrini JL, Baron TH, et al; ASGE/ACG Taskforce on Quality in Endoscopy. Quality indicators for colonoscopy. Am J Gastroenterol 2006;101:873-885.

2. Kaminski MF, Regula J, Kraszewska E, et al. Quality indicators for colonoscopy and the risk of interval cancer. $N$ Engl $J$ Med 2010;362:1795-1803.

3. Johnson DA, Barkun AN, Cohen LB, et al. Optimizing adequacy of bowel cleansing for colonoscopy: recommendations from the U.S. multi-society task force on colorectal cancer. Gastrointest Endosc 2014;80:543-562.

4. Saltzman JR, Cash BD, Pasha SF, et al; ASGE Standards of Practice Committee. Bowel preparation before colonoscopy. Gastrointest Endosc 2015;81:781-794.

5. Manes G, Amato A, Arena M, Pallotta S, Radaelli F, Masci E. Efficacy and acceptability of sodium picosulphate/magnesium citrate vs low-volume polyethylene glycol plus ascorbic acid for colon cleansing: a randomized controlled trial. Colorectal Dis 2013; 15:1145-1153.

6. Hamilton D, Mulcahy D, Walsh D, Farrelly C, Tormey WP, Watson G. Sodium picosulphate compared with polyethylene glycol solution for large bowel lavage: a prospective randomised trial. Br J Clin Pract 1996;50:73-75.

7. Huppertz-Hauss G, Bretthauer M, Sauar J, et al. Polyethylene glycol versus sodium phosphate in bowel cleansing for colonoscopy: a randomized trial. Endoscopy 2005;37:537-541.

8. Jansen SV, Goedhard JG, Winkens B, van Deursen CT. Preparation before colonoscopy: a randomized controlled trial comparing different regimes. Eur J Gastroenterol Hepatol 2011;23:897-902.

9. Kao D, Lalor E, Sandha G, et al. A randomized controlled trial of four precolonoscopy bowel cleansing regimens. Can J Gastroenterol 2011;25:657-662.

10. Ker TS. Comparison of reduced volume versus four-liter electrolyte lavage solutions for colon cleansing. Am Surg 2006;72:909-911.

11. Young CJ, Simpson RR, King DW, Lubowski DZ. Oral sodium phosphate solution is a superior colonoscopy preparation to polyethylene glycol with bisacodyl. Dis Colon Rectum 2000;43:1568-1571.

12. Vanner SJ, MacDonald PH, Paterson WG, Prentice RS, Da Costa LR, Beck IT. A randomized prospective trial comparing oral sodium phosphate with standard polyethylene glycol-based lavage solution (Golytely) in the preparation of patients for colonoscopy. Am J Gastroenterol 1990;85:422-427.

13. Rostom A, Jolicoeur E, Dubé C, et al. A randomized prospective trial comparing different regimens of oral sodium phosphate and polyethylene glycol-based lavage solution in the preparation of patients for colonoscopy. Gastrointest Endosc 2006;64:544-552.

14. Froehlich F, Wietlisbach V, Gonvers JJ, Burnand B, Vader JP. Impact of colonic cleansing on quality and diagnostic yield of colonoscopy: the European Panel of Appropriateness of Gastrointestinal Endoscopy European multicenter study. Gastrointest Endosc 2005;61:378-384.

15. Harewood GC, Sharma VK, de Garmo P. Impact of colonoscopy preparation quality on detection of suspected colonic neoplasia. Gastrointest Endosc 2003;58:76-79.

16. Bowles CJ, Leicester R, Romaya C, Swarbrick E, Williams CB, Epstein O. A prospective study of colonoscopy practice in the UK today: are we adequately prepared for national colorectal cancer screening tomorrow? Gut 2004;53:277-283.

17. Chokshi RV, Hovis CE, Hollander T, Early DS, Wang JS. Prevalence of missed adenomas in patients with inadequate bowel preparation on screening colonoscopy. Gastrointest Endosc 2012;75:1197-1203.

18. Rex DK, Imperiale TF, Latinovich DR, Bratcher LL. Impact of bowel preparation on efficiency and cost of colonoscopy. Am J 
Gastroenterol 2002;97:1696-1700.

19. Chan WK, Saravanan A, Manikam J, Goh KL, Mahadeva S. Appointment waiting times and education level influence the quality of bowel preparation in adult patients undergoing colonoscopy. BMC Gastroenterol 2011;11:86.

20. Taylor C, Schubert ML. Decreased efficacy of polyethylene glycol lavage solution (golytely) in the preparation of diabetic patients for outpatient colonoscopy: a prospective and blinded study. Am J Gastroenterol 2001;96:710-714.

21. Ness RM, Manam R, Hoen H, Chalasani N. Predictors of inadequate bowel preparation for colonoscopy. Am J Gastroenterol 2001;96:1797-1802.

22. Gimeno-García AZ, Baute JL, Hernandez G et al. Risk factors for inadequate bowel preparation: a validated predictive score. Endoscopy 2017;49:536-543.

23. Chung YW, Han DS, Park KH, et al. Patient factors predictive of inadequate bowel preparation using polyethylene glycol: a prospective study in Korea. J Clin Gastroenterol 2009;43:448-452.

24. Borg BB, Gupta NK, Zuckerman GR, Banerjee B, Gyawali CP. Impact of obesity on bowel preparation for colonoscopy. Clin Gastroenterol Hepatol 2009;7:670-675.

25. Lebwohl B, Wang TC, Neugut AI. Socioeconomic and other predictors of colonoscopy preparation quality. Dig Dis Sci 2010;55:2014-2020.

26. Hassan C, Fuccio L, Bruno M, et al. A predictive model identifies patients most likely to have inadequate bowel preparation for colonoscopy. Clin Gastroenterol Hepatol 2012;10:501-506.

27. Rex DK. Optimal bowel preparation-a practical guide for clinicians. Nat Rev Gastroenterol Hepatol 2014;11:419-425.

28. Kolts BE, Lyles WE, Achem SR, Burton L, Geller AJ, MacMath T.
A comparison of the effectiveness and patient tolerance of oral sodium phosphate, castor oil, and standard electrolyte lavage for colonoscopy or sigmoidoscopy preparation. Am J Gastroenterol 1993;88:12181223.Schiller LR. Clinical pharmacology and use of laxatives and lavage solutions. J Clin Gastroenterol 1999;28:11-18.

29. Heppner HJ, Christ M, Gosch M, et al. Polypharmacy in the elderly from the clinical toxicologist perspective. Z Gerontol Geriatr 2012;45:473-478.

30. Chorev N, Chadad B, Segal N, et al. Preparation for colonoscopy in hospitalized patients. Dig Dis Sci 2007;52:835-839.

31. Yadlapati R, Johnston ER, Gregory DL, Ciolino JD, Cooper A, Keswani RN. Predictors of inadequate inpatient colonoscopy preparation and its association with hospital length of stay and costs. Dig Dis Sci 2015;60:3482-3490.

32. Mahmood S, Farooqui SM, Madhoun MF. Predictors of inadequate bowel preparation for colonoscopy: a systematic review and metaanalysis. Eur J Gastroenterol Hepatol 2018;30:819-826.

33. Kilgore TW, Abdinoor AA, Szary NM, et al. Bowel preparation with split-dose polyethylene glycol before colonoscopy: a metaanalysis of randomized controlled trials. Gastrointest Endosc 2011;73:1240-1245.

34. Adler A, Wegscheider K, Lieberman D, et al. Factors determining the quality of screening colonoscopy: a prospective study on adenoma detection rates, from 12,134 examinations (Berlin colonoscopy project 3, BECOP-3). Gut 2013;62:236-241.

35. Lebwohl B, Kastrinos F, Glick M, Rosenbaum AJ, Wang T, Neugut AI. The impact of suboptimal bowel preparation on adenoma miss rates and the factors associated with early repeat colonoscopy. Gastrointest Endosc 2011;73:1207-1214. 